\title{
Anisotropy in Morphology and Crystal Structure of $\mathrm{BaTiO}_{3}$
}

\section{Nanoblocks}

\author{
Qiang Ma* and Kazumi Kato
}

National Institute of Advanced Industrial Science and Technology (AIST),

2266-98 Anagahora, Shimoshidami, Moriyama, Nagoya, 463-8560, Japan

Corresponding author:

Dr. Qiang Ma

Address: National Institute of Advanced Industrial Science and Technology (AIST),

2266-98 Anagahora, Shimoshidami, Moriyama, Nagoya, 463-8560, Japan

Phone: $+81-52-736-7577$

Fax: $\quad+81-52-736-7234$

e-mail: maqiang0710@gmail.com 
Single crystalline $\{100\}$ dominant $\mathrm{BaTiO}_{3}$ nanoblocks were synthesized by the hydrothermal method using aqueous sources of $\mathrm{Ba}$ and $\mathrm{Ti}$, and organic additives. $\mathrm{BaTiO}_{3}$ nanoblocks with neat surface and standard corner angle show two kinds of morphology, cubic and cuboid shapes. Based on TEM images of $\mathrm{BaTiO}_{3}$ nanoblocks, the percentage of nanocuboids improved from $24.3 \%$ to $51.8 \%$, as the average size of nanoblocks varied from $\sim 15 \mathrm{~nm}$ to $\sim 25 \mathrm{~nm}$. The asymmetric morphology of $\mathrm{BaTiO}_{3}$ nanocuboids reveals an anisotropic growth pattern. One straightforward method was employed to discuss the crystal phase of $\mathrm{BaTiO}_{3}$ nanocuboids by using the HR-TEM images and the corresponding FFT patterns. The d spacing of $\{100\}$ crystal planes show diverse values. The ratios of $d$ spacing of (100) crystal plane and the perpendicular (001) plane are larger than one. The short edge direction in $\mathrm{BaTiO}_{3}$ nanocuboids coincides with their [001] crystal orientation. According to the enlarged FFT filtered HR-TEM images, the shape and oriented array of the unit cells in nanocuboids played a crucial role on the formation of anisotropy in morphology. Co-considering the DSC result, the findings indicate the existence possibility of tetragonal phase in $\mathrm{BaTiO}_{3}$ nanocuboids with less than $30 \mathrm{~nm}$ size.

Keywords: $\mathrm{BaTiO}_{3}$ nanoblocks, nanocuboid, tetragonal phase, anisotropy, 


\section{Introduction}

Anisotropy of $\mathrm{BaTiO}_{3}$ nanomaterials has attracted much attention [1-3] owing to its vital role in tuning the shape and properties. The morphology of $\mathrm{BaTiO}_{3}$ nanomaterials is key factor to decide the ultimate performance of perovskite-based nanoelectronics [3-7]. In this regard, it is desirable to analyze the anisotropy in morphology of $\mathrm{BaTiO}_{3}$ nanomaterials and achieve their tailor-synthesis. Over the past decade, the anisotropic properties of one-dimensional or two-dimensional $\mathrm{BaTiO}_{3}$ nanomaterials with diversified morphologies have been investigated systematically [7-13]. However, few of reports focused on the anisotropy in the morphology of $\mathrm{BaTiO}_{3}$ nanoblocks with cuboid shape. Compared with one or two dimensional nanomaterials, $\mathrm{BaTiO}_{3}$ nanocuboids can provide a larger interface and a close-packing ordered architecture, which are crucial for "bottom-up" nanotechnology applications. The surface of $\mathrm{BaTiO}_{3}$ nanocuboids is dominated by six $\{100\}$ crystal plans. Their aspect ratios (length edge/width edge) are more than one and indicate an anisotropic growth process. Due to the highly symmetric limitation, it is difficult to synthesize amount of $\mathrm{BaTiO}_{3}$ nanocuboids. This has hindered the development of their investigation and applications. In this work, we synthesized batch of $\mathrm{BaTiO}_{3}$ nanocuboids and studied their anisotropy.

Due to the miniaturization of multilayer ceramic capacitors (MLCCs), much effort was paid to study the tetragonal phase and cubic phase of $\mathrm{BaTiO}_{3}$ nanocrystals [14-16]. Conventional $\mathrm{BaTiO}_{3}$ nanocrystals with irregular shape always show the cubic phase in the range of several tens nanometer, which is known as the so-called "size-effect". Moreover, the existence of impurities (lattice hydroxyl, carbonate, et.al) resulted in the decrease of the dielectric constant of $\mathrm{BaTiO}_{3}$ nanocrystals [17]. Recently, some groups 
explored the crystal phase of $\mathrm{BaTiO}_{3}$ nanocrystals with different size [17-20]. The results indicate that the tetragonal phase disappears gradually, as the size of $\mathrm{BaTiO}_{3}$ nanocrystals decreases from $140 \mathrm{~nm}$ to $30 \mathrm{~nm}$. The disappeared tetragonal phase and ferroelectric property of $\mathrm{BaTiO}_{3}$ nanocrystals are attributed to the surface relaxation and the expansion of lattice. Thus, how to realize the stable tetragonal phase of ultrafine $\mathrm{BaTiO}_{3}$ nanocrystals is one of important research targets for industrial applications. The previous report pointed out the net structure strain could cause the rotation of the $\mathrm{TiO}_{6}$ octahedral and change its bond length [21]. These structural deformation can result in the crystal phase transition of perovskite materials. The lattice strain can be induced in the anisotropic $\mathrm{BaTiO}_{3}$ nanocuboids during the nucleation and growth process. Thus, $\mathrm{BaTiO}_{3}$ nanocuboid is one of promising candidates to realize the tetragonal phase of perovskite materials in nano-scale.

In this work, high quality $\mathrm{BaTiO}_{3}$ nanoblocks were synthesized by hydrothermal method using aqueous sources and organic additives. The high-resolution transmission electron microscopy (HR-TEM) images and the corresponding fast Fourier transform (FFT) patterns were employed to study the anisotropy in morphology and the subtle difference in the lattice constants of $\mathrm{BaTiO}_{3}$ nanocuboids. The examination of individual $\mathrm{BaTiO}_{3}$ nanoblocks with regular cuboid shape and atomically flat surfaces provided a detailed glimpse of the crystalline structures at small accessible length scale.

\section{Experimental}

\subsection{Material synthesis}

Single crystalline $\{100\}$ dominant $\mathrm{BaTiO}_{3}$ nanoblocks were synthesized by the hydrothermal method using aqueous sources of $\mathrm{Ba}$ and $\mathrm{Ti}$ compound, which has been published previously [2, 22]. In a brief description, $\mathrm{Ba}(\mathrm{OH})_{2} \cdot 8 \mathrm{H}_{2} \mathrm{O}$ and TALH 
(Bis(ammonium lactate) titanium dihydroxide) were added into the distilled water and acted as the source materials. $\mathrm{NaOH}$ was used to control the $\mathrm{pH}$ value of the precursor solution. The concentration of $\mathrm{NaOH}$ is $1.2 \mathrm{M}$. Oleic acid and tert-butylamine acted as the surfactant and additives to control the shape of BT nanoblocks. The molar ratio of $\mathrm{Ba}, \mathrm{Ti}$, oleic acid and tert-butylamine is 1: 1: 8: 6 . The solution was filled into an auto sealed autoclave and heated at $220^{\circ} \mathrm{C}$ for $72 \mathrm{~h}$ under mechanical stirring. After cooled at room temperature, white powders were washed by ethanol for several times and collected by a centrifugation process. After drying, the precipitation was dispersed into mesitylene. The surface of $\mathrm{BaTiO}_{3}$ nanoblocks was covered by oleic acid moleculars. Owing to the role of the fatty molecular, the nanoblocks can disperse in mesitylene solution and form a suspension.

\subsection{Structural characterization}

X-ray diffractometry (XRD, Rigaku RINT-2100V) was employed to confirm the crystal property of $\mathrm{BaTiO}_{3}$ nanoblocks. The morphology of the prepared $\mathrm{BaTiO}_{3}$ nanoblocks was investigated by using a transmission electron microscopy (TEM; Model JEM-2010F, with an accelerating voltage of $200 \mathrm{kV}$ ). Differential scanning calorimetry (DSC; STA 7000) measurement on the $\mathrm{BaTiO}_{3}$ nanocubes was carried out under pure nitrogen environment.

\section{Results and discussion}

3. 1. Anisotropy in morphology of $\mathrm{BaTiO}_{3}$ nanoblocks

Fig. 1 shows the TEM images of $\mathrm{BaTiO}_{3}$ nanoblocks with different average size. It can be observed that the nanoblocks possess two kinds of morphologies: cubic shape and cuboid shape. The values of nanocuboids/total nanoblocks were obtained by taking a statistics of about 250 particles, which were selected randomly from TEM images. A 
nanoblock with an edge length of less than $20 \mathrm{~nm}$ was distinguished to belong to the group of the $\sim 25 \mathrm{~nm}$. As the average size of $\mathrm{BaTiO}_{3}$ nanoblocks varied from $\sim 15 \mathrm{~nm}$ to $\sim 25 \mathrm{~nm}$ increased, the values increased from about $24.3 \%$ to $51.8 \%$. This result manifests the amount of $\mathrm{BaTiO}_{3}$ nanocuboid increased gradually. Based on the analysis of TEM images, the size-dependent values of cuboid / total nanoblocks were attributed to the anisotropy growth of $\mathrm{BaTiO}_{3}$ nanoblocks. The aspect ratios of these nanoblocks were measured and displayed in Fig. 1 (c) and (d). The average values of $\sim 25 \mathrm{~nm}$ group and $\sim 15 \mathrm{~nm}$ group were $\sim 1.23$ and $\sim 1.07$, respectively. The result indicates that the aspect ratio of $\mathrm{BaTiO}_{3}$ nanocuboids also shows a size-dependence property. In addition, since the nanocuboids existed in the final product, the self-assembly of nanoblocks with orderly arrangement might be achieved by precisely tuning the evaporation rate of solvents [23].

HR-TEM images can provide valuable information regarding the anisotropy in morphology and the crystal phases of the $\mathrm{BaTiO}_{3}$ nanoblocks. Fig. 2 displays the HRTEM images of four randomly-selected $\mathrm{BaTiO}_{3}$ nanoblocks with clear cuboid shape. The lengths of the long edge $\left(\mathrm{L}_{\mathrm{L}}\right)$ direction and the short edge $\left(\mathrm{L}_{\mathrm{S}}\right)$ direction in mono-dispersed $\mathrm{BaTiO}_{3}$ nanocuboids were measured and shown in the Fig. 2. The values of $\mathrm{L}_{\mathrm{L}} / \mathrm{L}_{\mathrm{S}}$ are larger than one and display the anisotropy in morphology of $\mathrm{BaTiO}_{3}$ nanocuboids. According to the Gibbs-Curie-Wulff theory, the crystal growth rate along a certain crystallographic orientation is proportional to the surface energy [24]. The morphology of nanocrystals is determined by the facet with the minimum surface energy. To tailor the final shape of nanocrystals, the affinity of surfactants is employed to modulate the growth rates of different crystal directions [25]. Recently, the anisotropy of nano-sized transition metal oxide was studied and the fatty acid was used 
as surfactant $[26,27]$. In our case, barium ions are denser of the (100) facets and the oleic acid molecules bind preferentially the Ba ions. [2, 22]. Based on the FFT pattern (inset of Fig. 2), the surfaces of nanoblocks are dominated by $\{100\}$ crystal planes. If all of these $\{100\}$ crystal planes possess the equal growth rate, nanoblocks with symmetrical cubic morphology will be synthesized. However, the existence of nanocuboids indicates the difference in the growth speed of the six $\{100\}$ facet. The corresponding inverse FFT images of Fig. 2 (e) and (f) provide the detailed information for the lattices of $\mathrm{BaTiO}_{3}$ nanocuboids. The number of stacking lattices in different directions can be calculated or counted one by one easily. Due to the weak scattering for electron beam, oxygen atoms are difficult to be detected by HR-TEM observation. As exhibited in the filtered images, the difference in the number of stacking lattices in different directions $\left(\mathrm{L}_{\mathrm{L}}\right.$ and $\left.\mathrm{L}_{\mathrm{S}}\right)$ indicates an anisotropic growth pattern of nanocuboids $[25,27]$. Moreover, the difference is enlarged with the increase of the size of nanocuboids. As mentioned above, the results of Fig. 1 (c) and (d) manifest the size-dependent property of the aspect ratio of nanoblocks. The observation in HR-TEM course confirms this property of $\mathrm{BaTiO}_{3}$ nanocuboids in atomic scale.

\section{2. Crystal Structure of $\mathrm{BaTiO}_{3}$ nanocuboids}

The crystal phases of mono-dispersed $\mathrm{BaTiO}_{3}$ nanocuboids were analyzed in detail by using HR-TEM and the corresponding FFT patterns. One kind of straightforward method was employed to discuss the crystalline structure of single $\mathrm{BaTiO}_{3}$ nanocuboids. The values of $\mathrm{d}$ spacing of different crystal faces in $\mathrm{BaTiO}_{3}$ nanocuboids were calculated by using the corresponding reciprocal lattice spots in the FFT patterns. Diverse values of the d spacing of different crystal planes are displayed in Fig. 3. In the same $\mathrm{BaTiO}_{3}$ nanocuboids, the values of the $\mathrm{d}$ spacing in $\mathrm{L}_{\mathrm{S}}$ direction are larger than 
those in $\mathrm{L}_{\mathrm{L}}$ direction. The ratios of $\mathrm{d}$ spacing of (100) crystal plane and the perpendicular (001) plane are in a range of 1.014 1.018. The results are coincident with those of previous reports, which focus on the tetragonal phase of $\mathrm{BaTiO}_{3}$ [28-30]. As well known, the DSC technique is low sensitive for small amount of tetragonality in nanomaterials. In previous reports, Begg et al. pointed out that the DSC peak disappeared when the $\mathrm{BaTiO}_{3}$ possessed a tetragonality cla less than 1.0061 [30]. Combined with the DSC result (Fig. 6), the FFT results can indicate the presence of an amount of the tetragonality in $\mathrm{BaTiO}_{3}$ nanocuboids. To confirm the calculating results of FFT pattern, the FFT filtered HR-TEM images were utilized to directly measure the d spacing of $\{100\}$ crystal faces. The corresponding inverse FFT images (Fig. 3 (c), (d) and $(\mathrm{g}),(\mathrm{h}))$ provide the detailed information of the lattices of $\mathrm{BaTiO}_{3}$ nanocuboids. The lattice fringes in different directions can be observed easily. Ten layers of the crystal lattices in different directions were selected to decrease the measurement error. As displayed in the enlarged images of Fig. 3, the measured values of $\mathrm{d}$ spacing are corresponding with those of the FFT pattern.

As for tetragonal $\mathrm{BaTiO}_{3}$, there is an average relative displacement along the $c$-axis of titanium (Ti) cation from its centrosymmetric position (as shown in Fig. 4 (a)). This displacement brings the creation of a polarization of $26 \mu \mathrm{C} / \mathrm{cm}^{2}$ along the $<001>$ direction [17, 20, 31, 32], and induces residual strain in $\mathrm{BaTiO}_{3}$ [33]. Xia, et.al mentioned that the internal strain in the lattice was related with the anisotropic growth of nanocrystals [34]. In our case, co-considering the value of lattice constant in different direction of nanocuboids and the result of DSC, the displacements of Ti cations occurred in $\mathrm{BaTiO}_{3}$ nanocuboids. The Ti cations were displaced in the [001] direction in the tetragonal phase. The enlarged FFT filtered image of Fig. 3 (d) and (h) shows a 
series of parallel straight lattice fringes, which indicates the oriented array of unit cells with displaced Ti cations. Based on the Ostwald ripening theory, the lattice structure of nanocrystals is close to perfection as much as possible to decrease the total Gibbs free energy. If the array of unit cell is random, owe to the difference in lattice spacing between a-axis and c-axis, some defects (edge dislocation, stacking dislocation, etc) will be formed in $\mathrm{BaTiO}_{3}$ nanocuboids and induce the increased total free energy. Moreover, the polarization of unit cells can result in the formation of the dipoles, which will promote their ordered array. Thus, the direction of unit cell array is oriented in the nanoblocks (marked in Fig. 4 (b)). The displacement of $\mathrm{Ti}^{4+}$ cations causes the lattice stretch of unit cell in [001] orientation (as shown by Fig. 4(a)). When unit cells with rectangular shape array in order and constitute one nanocuboid, the long side of nanocuboid might be easily recognized as be parallel with the [001] crystal direction. However, it is interested that the stretch direction of unit cells is perpendicular to the $\mathrm{L}_{\mathrm{L}}$ direction of nanocuboids. And the Ls direction is coincident with the [001] crystal orientation. Observing precisely the filtered images of Fig. 3, the number of stacking layers in the Ls direction is obviously smaller than that in the $\mathrm{L}_{\mathrm{L}}$ direction. The difference in the number of stacking lattice in [100] orientation and the perpendicular [001] orientation results in the formation of nanocuboids. It is considered that the disparity of the number of stacking layers is associated with the shape and ordered arrangement of unit cells. As unit cells with the displaced $\mathrm{Ti}^{4+}$ cations array orderly in $\mathrm{BaTiO}_{3}$ nanocuboids, the cubic symmetric structures transform into the distorted ferroelectric structures. This distortion of crystalline structures will introduce the lattice strain into the inner section of nanocuboids. As for tetragonal $\mathrm{BaTiO}_{3}$ nanocuboids, the strain exists in [001] crystal direction. The relationship between the strain and 
polarization of $\mathrm{BaTiO}_{3}$ has been calculated from first-principles [35]. If the polarization is larger than $20 \mu \mathrm{C} / \mathrm{cm}^{2}$, the strain reaches about $3.5 \mathrm{E}-3 \%$. Based on the calculated elastic constants of the tetragonal phase, the stress is $\sim 0.5 \mathrm{GPa}$. The strain can influence the growth rate of stacking lattice in [001] crystal orientation. Thus, the nanoblocks will tend to select the other growth directions during ripening process. The stacking rate of lattice layers in [001] orientation is smaller than that in the other crystal orientations. Due to the role of oleic acid, only $\{100\}$ crystal faces are protected and the $\mathrm{L}_{\mathrm{L}}$ and Ls sides are formed after growing process. After nanocuboids are produced, their $\mathrm{L}_{\mathrm{L}}$ sides are perpendicular with [001] direction. As displayed Fig. 1(b), 2 and 3, the values of $\mathrm{L}_{\mathrm{L}}$ of $\mathrm{BaTiO}_{3}$ nanocuboids are not less than $\sim 24 \mathrm{~nm}$, and those of Ls vary from $\sim 15 \mathrm{~nm}$ to $\sim 23 \mathrm{~nm}$. This result indicates that the $\mathrm{BaTiO}_{3}$ nanocuboids prefer to grow along [100] orientation to obtain small lattice strain and low strain energy. Furthermore, it is conjectured that the strain confined the length of Ls no larger than $23 \mathrm{~nm}$ for 72 hours hydrothermal process. The anisotropy in shape of nanocuboids is able to be observed as the values of $\mathrm{L}_{\mathrm{L}}$ increased about $24 \mathrm{~nm}$. Owing to the role of strain, the growth rate on Ls direction is unstable and not uniform for different samples. Then, the length of Ls varies in a wide range. According to above discussion, the anisotropy in morphology and the tetragonal crystal phase of $\mathrm{BaTiO}_{3}$ nanocuboids are related with the shape and ordered array of unit cell.

Fig. 5 displays two-dimensional unit cells and one nanoblock with pseudo-cuboid shape. Because the density of barium ions on the $\{100\}$ facets is higher than on the other crystal facets, the $\{100\}$ facets are protected by the adsorption of oleic acid [2, 22]. The surface in the complete section of nanoblock is composed by $\{100\}$ crystal planes. Step and terrace structures are clearly observed in the incomplete section of the 
nanoblock, marked by red arrows in Fig. 5 (b), and the height of the each step is identical to one or two unit cells. It can be considered that the nanoblock is in the growing process. As displayed in Fig. 5 (c), the formation of nanoblocks is associated with the array of unit cells.

\section{3. DSC measurement of $\mathrm{BaTiO}_{3}$ nanoblocks}

As one thermo-analytical technique, the DSC measurement can be used to test the crystal phase transition of nanocrystals. The scan rate in the thermal analysis process is $2^{\circ} \mathrm{C} / \mathrm{min}$. In this study, the DSC measurement was carried out to confirm the phase transition of $\mathrm{BaTiO}_{3}$ nanoblocks and shown in Fig. 6. The testing temperature range is from $273 \mathrm{~K}$ to $423 \mathrm{k}$. To eliminate the influence of the capping organic materials on the surface of samples, the nanoblocks pre-treated at $500^{\circ} \mathrm{C}$ for 30 min under oxygen gas ambience before DSC measurement. It should be noted that the pre-treatment had no effect on the shape of nanoblocks. The morphology of $\mathrm{BaTiO}_{3}$ nanoblocks with and without the pre-treatment at $500^{\circ} \mathrm{C}$ for 30 min under oxygen gas ambience was observed by FE-SEM and displayed in Fig S1. The cubic or cuboid shape of BT nanoblocks could be retained after heat treatments. The Fig. 6 shows a broad exothermic peak starting from $\sim 75.3^{\circ} \mathrm{C}$, which corresponds to a phase transition from tetragonal phase to cubic phase. The DDSC graph is used to show the differential of DSC value, and a sharp peak is in the graph. Previous reports has proved that the nanocubes with $10 \sim 15 \mathrm{~nm}$ size possess ferroelectric properties at room temperature $[2,18]$. It is well known that the ferroelectric to paraelectric transition is almost corresponding to the phase transition temperature of $\mathrm{BaTiO}_{3}$ materials. The findings in DSC graph indicate that the ferroelectric transition of nanoblocks is distributed over a wide range of temperatures $[29,36]$, and belongs to a diffused phase transition [37]. Thus, the synthesized $\mathrm{BaTiO}_{3}$ 
nanoblocks are behaving as "ferroelectric relaxor" materials. In addition, the previous study illustrated that the phase-transition temperature of perovskite $\mathrm{BaTiO}_{3}$ is size-dependent [38].

\section{4. HR-TEM of $\mathrm{BaTiO}_{3}$ nanocube}

The crystal phases of one representative $\mathrm{BaTiO}_{3}$ nanocube was analyzed in detail by using HR-TEM and the corresponding FFT patterns, as shown in Fig. 7. The edge morphology of nanocube also shows the step or terrace structure. All of steps start from the corner section and forward to the central portion of the edge of nanocubes, which forms a slight concave cubic shape (as in Fig. 7 (b)). The direction of four corners of nanocubes belongs to $<110>$ crystal direction. This result shows that the growth rate on $<110\rangle$ direction is faster than that on $\langle 100\rangle$ direction. Furthermore, the height of steps and the superimposed terraces indicate that the ordered arrangement of unit cells is related with the surface morphology and shape of the nanocubes. The values of $d$ spacing of $\mathrm{BaTiO}_{3}$ nanocube are calculated by using the FFT patterns and measured by the FFT filtered HR-TEM images. The ratio of d spacing is 1.001 , which indicates the existence of cubic phase. Combining with above discussions, it is conjectured that the crystalline phases of $\mathrm{BaTiO}_{3}$ nanoblocks possess both tetragonal and cubic phases.

\section{Conclusion}

The $\mathrm{BaTiO}_{3}$ nanoblocks with different average size were synthesized by using hydrothermal method and showed both cubic and cuboid shapes. Anisotropy in morphology of single crystalline $\mathrm{BaTiO}_{3}$ nanocuboids with neat surface and standard corner angle was investigated by precise analysis of TEM and HR-TEM images. The aspect ratios of $\mathrm{L}_{\mathrm{L}} / \mathrm{L}_{\mathrm{S}}$ of mono-nanoblocks are counted by utilizing the TEM images. The $15 \mathrm{~nm}$ - and $25 \mathrm{~nm}$-sized nanoblocks contain around $24.3 \%$ and $51.8 \%$ of 
nanocuboids, respectively. Based on the precise analysis of the nanoblocks by using HR-TEM, the unique morphology of nanocuboids appeared an anisotropy growth pattern.

The lattice constant of $\mathrm{BaTiO}_{3}$ nanoblocks was measured by using the HR-TEM images directly and calculated by using the corresponding FFT pattern. The ratios of $d$ spacing of (100) crystal plane and the perpendicular (001) plane varied from $\sim 1.014$ to 1.018. The existence of $\mathrm{BaTiO}_{3}$ nanocuboid indicates the possibility of the existence of the tetragonal phase in the nano-scale range.

\section{Acknowledgements:}

This work was supported by the Advanced Low Carbon Technology Research and Development Program (ALCA) of Japan Science and Technology Agency (JST).

\section{References:}

1 J. E. Spanier, A. M. Kolpak, J. J. Urban, I. Grinberg, L. Ouyang, W. S. Yun, A. M. Rappe, H. k. Park, Ferroelectric Phase Transition in Individual Single-Crystalline $\mathrm{BaTiO}_{3}$ Nanowires, Nano Lett. 6 (2006) 735-739.

2 K. Kato, F. Dang, K. Mimura, Y. Kinemuchi, H. Imai, S. Wada, M. Osada, H. Haneda, M. Kuwabara, Nano-sized cube-shaped single crystalline oxides and their potentials; composition, assembly and functions, Adv. Powder Technol. 25 (2014) 1401-1414.

3 L. Jiang, A. Betts, D. Kennedy, S. Jerrams, Improving the electromechanical performance of dielectric elastomers using silicone rubber and dopamine coated barium titanate, Mater \& Des 85 (2015) 733-742.

4 S.-G. Lee, U. Paik, Y. Shin, J.-W. Kim, Y.-G. Jung, Control of residual stresses with post process in $\mathrm{BaTiO}_{3}$-based Ni-MLCCs, Mater \& Des 24 (2003) 169-176.

5 Z. Wen, C. Li, D. Wu, A. D. Li, N. B. Ming, Ferroelectric-field-effect-enhanced electroresistance in metal/ferroelectric/semiconductor tunnel junctions, Nat. Mater. 12 (2013) 617-621.

6 P. Tang, D. J. Towner, A. L. Meier, B. W. Wessels, Low-voltage, polarization-insensitive, electro-optic modulator based on a polydomain barium titanate thin film, Appl. Phys. Lett. 85 (2004) 4615-4617.

7 Y. H. Zhang, J. W. Hong, B. Liu, D. N. Fang, Strain effect on ferroelectric behaviors of BaTiO3 nanowires: a molecular dynamics study, Nanotechnology, 21 (2010) 015701-6.

8 B. K. Lee, S. Y. Chung, S. J. Kang, Grain boundary faceting and abnormal grain growth in $\mathrm{BaTiO}_{3}$, Acta Mater 48 (2000) 1575-1580. 
9 A. Lamberti, N. Garino, B. Katarzyna, S. Bianco, S. Stassi, A. Chiodoni, G. Canavese, C. F. Pirri, M. Quaglio, Synthesis of ferroelectric $\mathrm{BaTiO}_{3}$ tube-like arrays by hydrothermal conversion of a vertically aligned $\mathrm{TiO}_{2}$ nanotube carpet, New J. Chem., 38 (2014) 2024-2030.

10 J. Yang, J. Zhang, C. Y. Liang, M. Wang, P. F. Zhao, M. M. Liu, J. W. Liu, R. C. Che, Ultrathin $\mathrm{BaTiO}_{3}$ Nanowires with High Aspect Ratio: A Simple One-Step Hydrothermal Synthesis and Their Strong Microwave Absorption, ACS Appl. Mater. Interfaces. 5 (2013) 7146-7151.

11 U. A. Joshi, J. S. Lee, Template-free hydrothermal synthesis of single-crystalline barium titanate and strontium titanate nanowires, Small. 1 (2005) 1172-1176.

12 M. Niederberger, G. Garnweitner, N. Pinna, M. Antonietti, Nonaqueous and Halide-Free Route to Crystalline $\mathrm{BaTiO}_{3}, \mathrm{SrTiO}_{3}$, and $(\mathrm{Ba}, \mathrm{Sr}) \mathrm{TiO}_{3}$ Nanoparticles via a Mechanism Involving $\mathrm{C}-\mathrm{C}$ Bond Formation, J. Am. Chem. Soc. 126 (2004) 9120-9126

13 W. J. Dong, B. J. Li, Y. Li, X. B. Wang, L. An, C. R. Li, B. Y. Chen, G. Wang, Z. Shi, General Approach to Well-Defined Perovskite $\mathrm{MTiO}_{3}(\mathrm{M}=\mathrm{Ba}, \mathrm{Sr}, \mathrm{Ca}$, and $\mathrm{Mg}$ ) Nanostructures, J. Phys. Chem. C. 115 (2011) 3918-3925.

14 M. K. Han, Y. C. Rong, Q. Li, X. R. Xing, L. T. Kang, Thermal expansion of nano-sized $\mathrm{BaTiO}_{3}$, CrystEngComm, 17 (2015) 1944-1951.

15 V. Bansal, P. Poddar, A. Ahmad, M. Sastry, Room-temperature biosynthesis of ferroelectric barium titanate nanoparticles, J. Am. Chem. Soc. 128 (2006) 11958-11963.

16 F. A. Rabuffetti, R. L. Brutchey, Structural Evolution of $\mathrm{BaTiO}_{3}$ Nanocrystals Synthesized at Room Temperature, J. Am. Chem. Soc. 134 (2012) 9475- 9487.

17 S. H. Yoon, M. Y. Kim, C. H. Nam, J. W. Seo, S. K. Wi, K. H. Hur, Grain-growth effect on dielectric nonlinearity of $\mathrm{BaTiO}_{3}$-based multi-layer ceramic capacitors, Appl. Phys. Lett. 107 (2015) 072906-5.

18 M. J. Polking, M. G. Han, A. Yourdkhani, V. Petkov, C. F. Kisielowski, V. V. Volkov, Y. M. Zhu, G. Caruntu, A. P. Alivisatos, R. Ramesh, Ferroelectric order in individual nanometre-scale crystals, Nat. Mater. 11 (2012) 700-709.

19 M. L. Moreira, G. P. Mambrini, D. P. Volanti, E. R. Leite, M. O. Orlandi, P. S. Pizani, V. R. Mastelaro, C. O. Paiva-Santos, E. Longo, J. A. Varela, Hydrothermal Microwave: A New Route to Obtain Photoluminescent Crystalline $\mathrm{BaTiO}_{3}$ Nanoparticles, Chem. Mater. 20 (2008) 5381-5387.

20 M. B. Smith, K. Page, T. Siegrist, P. L. Redmond, E. C. Walter, R. Seshadri, L. E. Brus, M. L. Steigerwald, Crystal Structure and the Paraelectric-to-Ferroelectric Phase Transition of Nanoscale $\mathrm{BaTiO}_{3}$, J. Am. Chem. Soc. 130 (2008) 6955-6963.

21 C. L. Yuan, S. L. Ye, W. Lei, Strain induced tetragonal $\mathrm{SrTiO}_{3}$ nanoparticles at room temperature, Appl. Phys. Lett. 101 (2012) 071909-4.

22 Q. Ma, K. Mimura, K. Kato, Tuning shape of barium titanate nanocubes by combination of oleic acid/tert-butylamine through hydrothermal process, J. Alloys Compd., 655 (2016) 71-78.

23 Y. Nakagawa, H. Kageyama, Y. Oaki, H. Imai, Direction Control of Oriented Self-Assembly for 1D, 2D, and 3D Microarrays of Anisotropic Rectangular Nanoblocks, J. Am. Chem. Soc. 136 (2014) 3716-3719.

24 T. D. Nguyen, T. O. Do, General Two-Phase Routes to Synthesize Colloidal Metal Oxide Nanocrystals: Simple Synthesis and Ordered Self-Assembly Structures, J. phys. Chem. C. 113 (2009) 11204-11214. 
25 W. L. Shi, Y. Sahoo, H. Zeng, Y. Ding, M. T. Swihart, P. N. Prasad, Anisotropic Growth of PbSe Nanocrystals on $\mathrm{Au}-\mathrm{Fe}_{3} \mathrm{O}_{4}$ Hybrid Nanoparticles, Adv. Mater. 18 (2006) 1889-1894.

26 G. D. Liu, S. J. Liang, W. M. Wu, R. Lin, N. Q, R. W. Liang, Template-free synthesis of a $\mathrm{CdSnO}_{3} \cdot 3 \mathrm{H}_{2} \mathrm{O}$ hollow-nanocuboid photocatalyst via a facile microwave hydrothermal method, Nanotechnology 24 (2013) 255601-9.

27 L. H. Hu, C. Wang, S. Lee, R. E. W, L. D. Marks, K. R. Poeppelmeier, SrTiO3 Nanocuboids from a Lamellar Microemulsion, Chem. Mater, 25 (2013) 378-384.

28 R. Asiaie, W. D. Zhu, S. A. Akbar, P. K. Dutta, Characterization of submicron particles of tetragonal $\mathrm{BaTiO}_{3}$, Chem. Mater. 8 (1996) 226-234.

29 M. R. Joung, J. S. Kim, M. E. Song, J. H. Choi, S. Nahm, C. H. Choi, T. H. Sung, Synthesis of highly tetragonal $\mathrm{BaTiO}_{3}$ nanopowders by a two-step alkoxide-hydroxide route, J. Alloys and Compounds 509 (2011) 9089-9092.

30 B.D. Begg, E.R. Vance, J. Nowotny, Effect of Particle Size on the Room-Temperature Crystal Structure of Barium Titanate, J. Am. Ceram. Soc. 77 (1994) 3186-3192.

31 L. Ju, T. Sabergharesou, K. G. Stamplecoskie, M. Hegde, T. Wang, N. A. Combe, H. Y. Wu, P. V. Radovanovic, Interplay between Size, Composition, and Phase Transition of Nanocrystalline $\mathrm{Cr}^{3+}$-Doped $\mathrm{BaTiO}_{3}$ as a Path to Multiferroism in Perovskite-Type Oxides, J. Am. Chem. Soc. 134 (2012) 1136-1146.

32 M. T. Buscaglia, C. Harnagea, M. Dapiaggi, V. Buscaglia, A. Pignolet, P. Nanni, Ferroelectric $\mathrm{BaTiO}_{3}$ Nanowires by a Topochemical Solid-State Reaction, Chem. Mater. 21 (2009) 5058-5065.

33 R. C. Rogan, N. Tamura, G. A. Swift, E. ÜstÜndag, Direct measurement of triaxial strain fields around ferroelectric domains using X-ray microdiffraction, Nat. Mater. 2 (2003) 379-381.

34 Y. G. Sun, B. Mayers, T. Herricks, Y. N. Xia, Polyol Synthesis of Uniform Silver Nanowires: A Plausible Growth Mechanism and the Supporting Evidence, Nano Lett. 3 (2003) 955-960.

35 J. J. Wang, F. Y. Meng, X. Q. Ma, M. X. XU, L. Q. Chen, Lattice, elastic, polarization, and electrostrictive properties of $\mathrm{BaTiO}_{3}$ from first-principles, J. Appl. Phys. 108 (2010) 034107-6.

36 V. Bansal, P. Poddar, A. Ahmad, M. Sastry, Room-Temperature Biosynthesis of Ferroelectric Barium Titanate Nanoparticles, J. Am. Chem. Soc. 128 (2006) 11958-11963.

37 S. Chattopadhyay, P. Ayyub, V. R. Palkar, M. Multani, Size-induced diffuse phase transition in the nanocrystalline ferroelectric $\mathrm{PbTiO}_{3}$, Phys. Rev. B. 52 (1995) 13177-13183.

38 M. H. Frey, D. A. Payne, Grain-size effect on structure and phase transformations for barium titanate, Phys. Rev. B. 54 (1996) 3158-3168. 
Fig. 1 TEM images of $\mathrm{BaTiO}_{3}$ nanoblocks with an average size of (a) $15 \mathrm{~nm}$ and (b) 25 $\mathrm{nm}$; aspect ratio of (c) $15 \mathrm{~nm}$ nanoblocks and (d) $25 \mathrm{~nm}$ nanoblocks.

Fig. 2 (a), (b), (c) and (d) the HR-TEM images of four $\mathrm{BaTiO}_{3}$ nanoblocks with diversified aspect ratios; (e) and (f) the corresponding FFT filtered images of (b) and (d), respectively.

Fig. 3 HR-TEM images and corresponding FFT patterns of $\mathrm{BaTiO}_{3}$ nanocuboids with (a) a size of $\sim 18 \mathrm{~nm}$ and (e) a size of $\sim 28 \mathrm{~nm}$; (b) and (f) the FFT pattern of (a) and (e); (c) and (g) the corresponding FFT filtered images of (a) and (e); (d) and (h) the partial enlarged images of (c) and (g), respectively.

Fig. 4 Illustration for (a) the cubic phase and tetragonal phase of $\mathrm{BaTiO}_{3}$ nanocuboids, (b) the array of unit cells with the displaced Ti cations in $\mathrm{BaTiO}_{3}$ nanocuboids.

Fig. 5 (a) TEM image and (b) HR-TEM image of $\mathrm{BaTiO}_{3}$ nanoblocks with pseudo-cuboid shape; (c) HR-TEM image of the section in the square box of (a).

Fig. 6 DSC graphs of $\mathrm{BaTiO}_{3}$ nanoblocks with an average size of $30 \mathrm{~nm}$, which were pre-treated at $500^{\circ} \mathrm{C}$ for 30 min under oxygen gas ambience.

Fig. 7 (a) HR-TEM image of $\mathrm{BaTiO}_{3}$ nanocubes with a size of $~ 23 \mathrm{~nm}$; (b) Schematic diagram of $\mathrm{BaTiO}_{3}$ nanocubes; (c) corresponding FFT filtered image of (a); (c) the partial enlarged images of (b), the length of the scale bar is $5 \mathrm{~nm}$. 

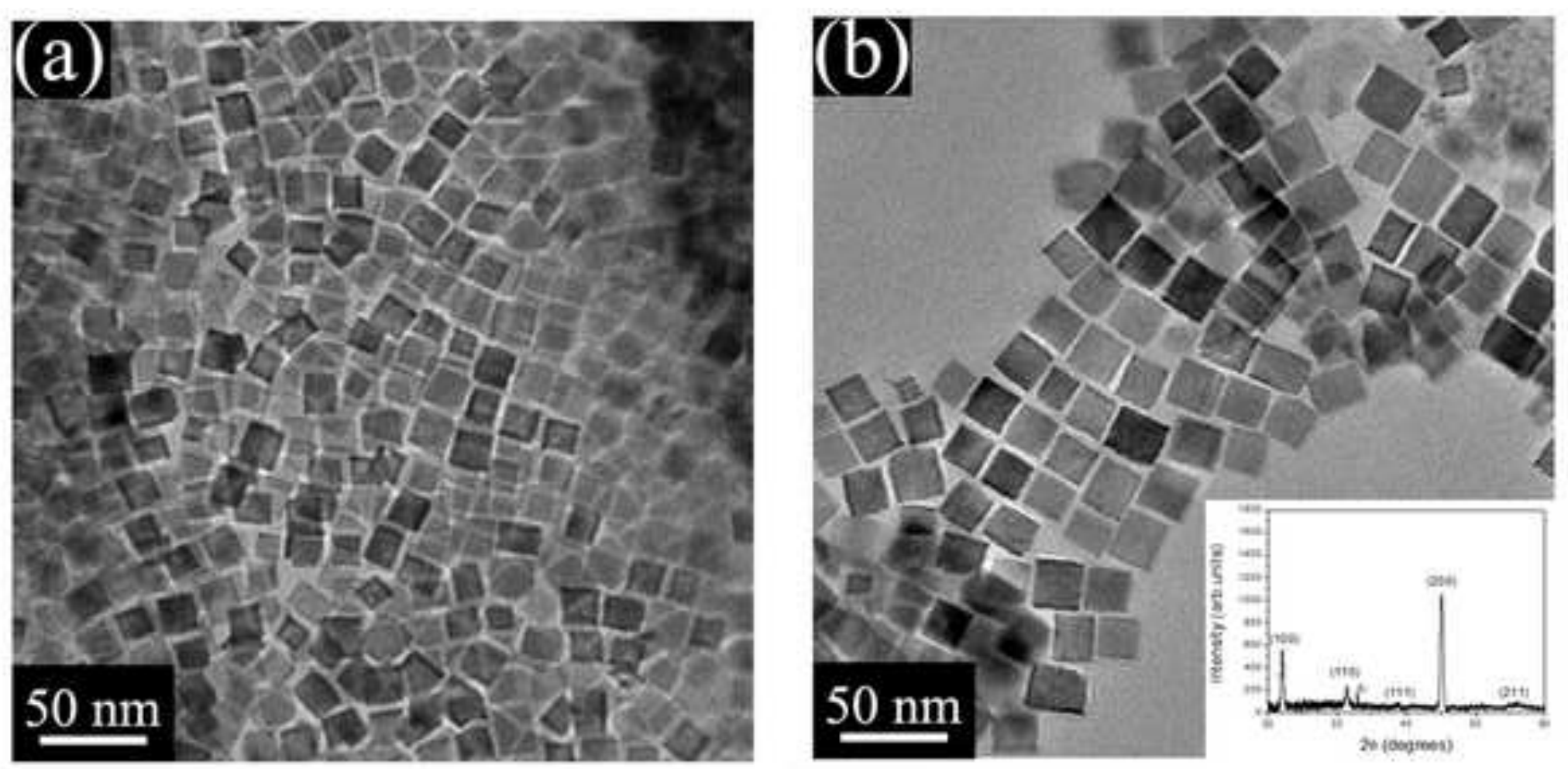

(c)
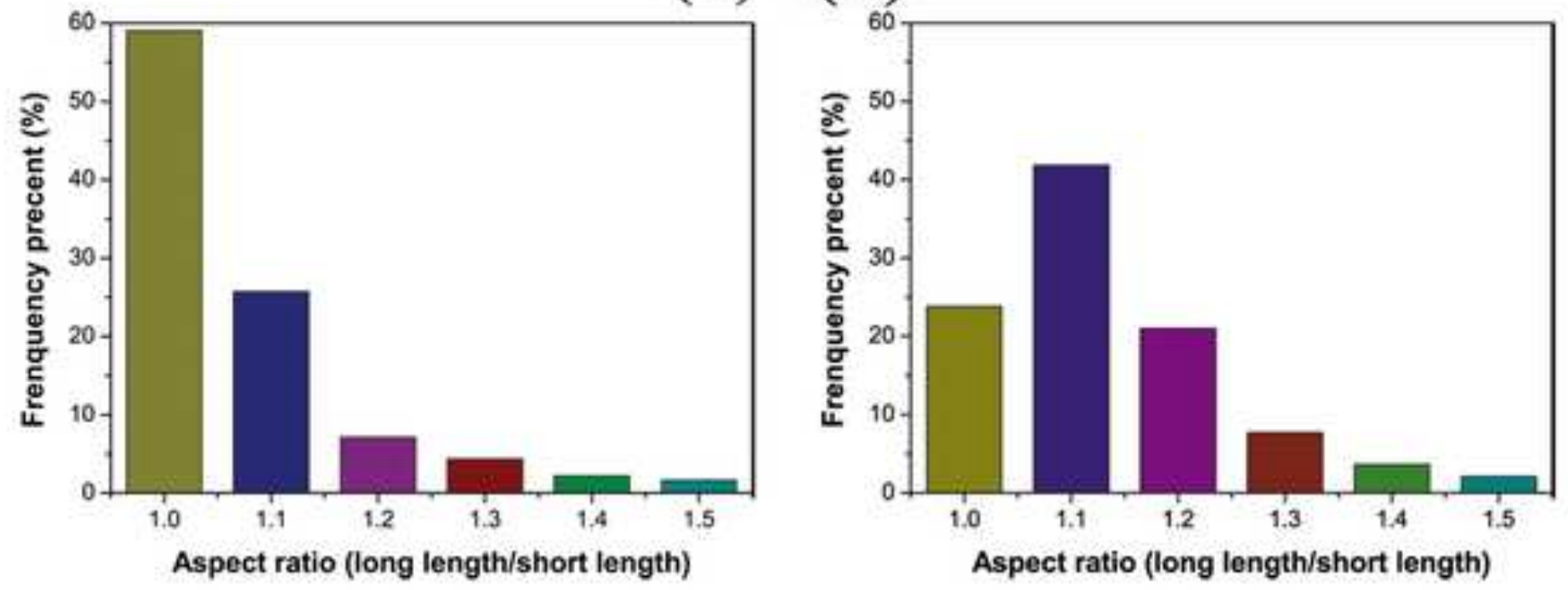

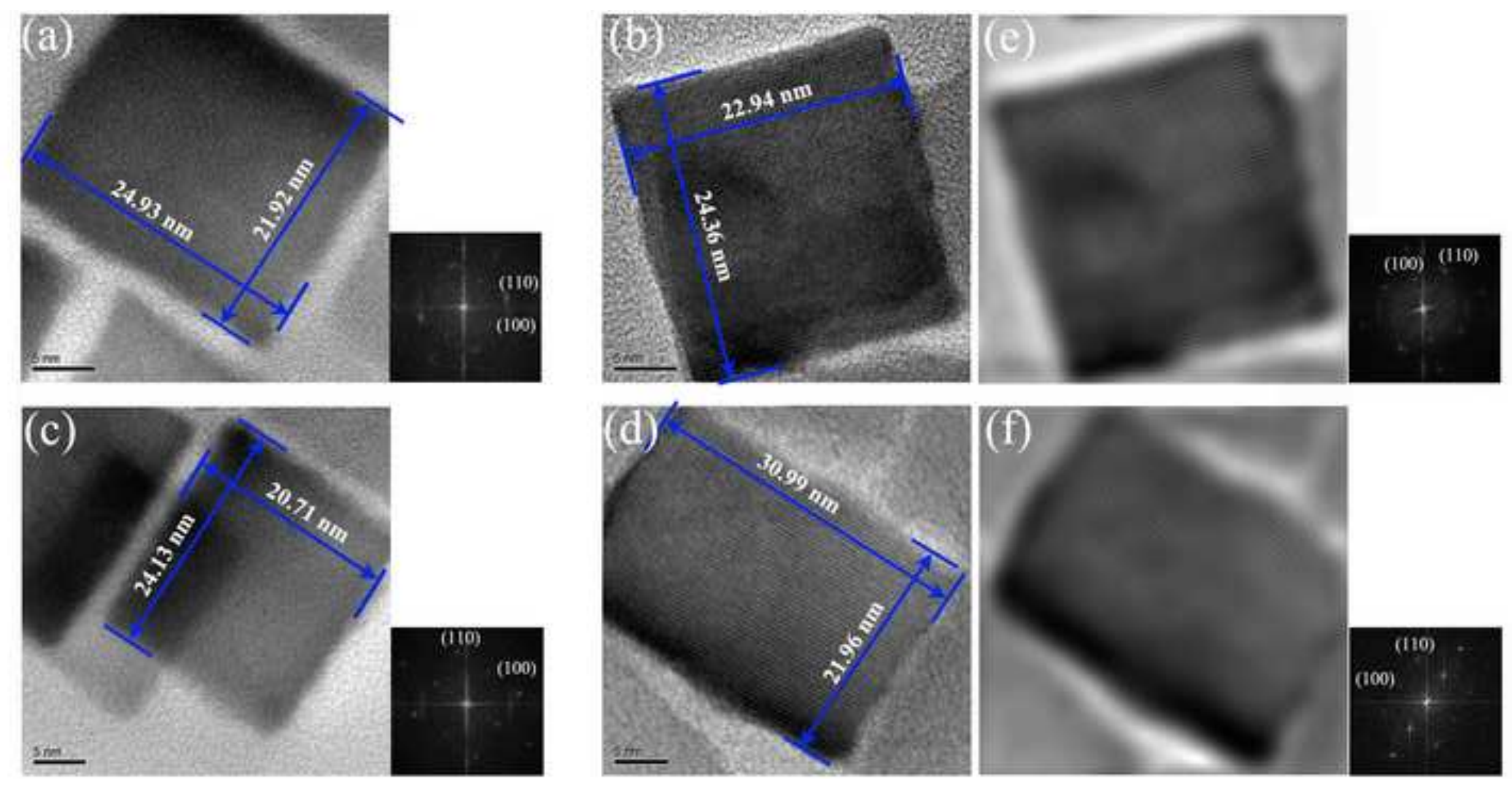

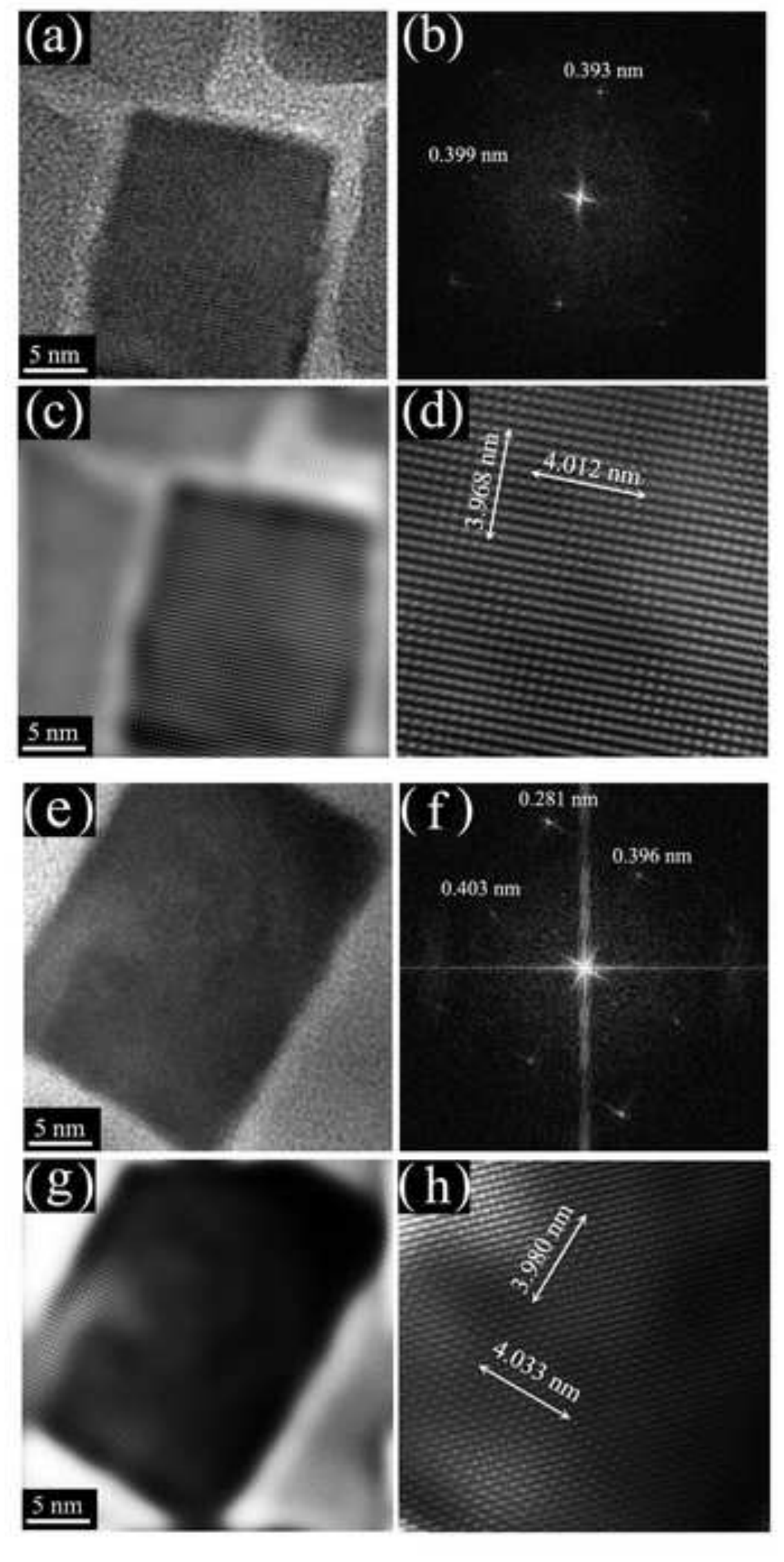

Figure 3 
(a)

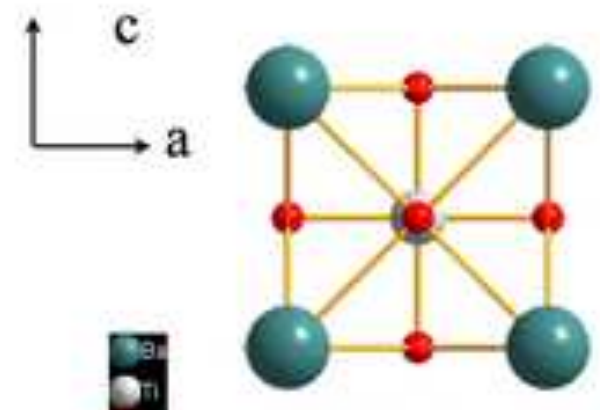

Cubic phase

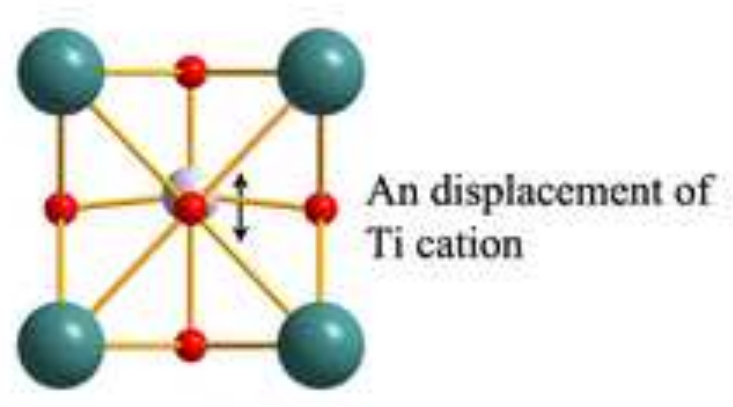

Tetragonal phase

(b)

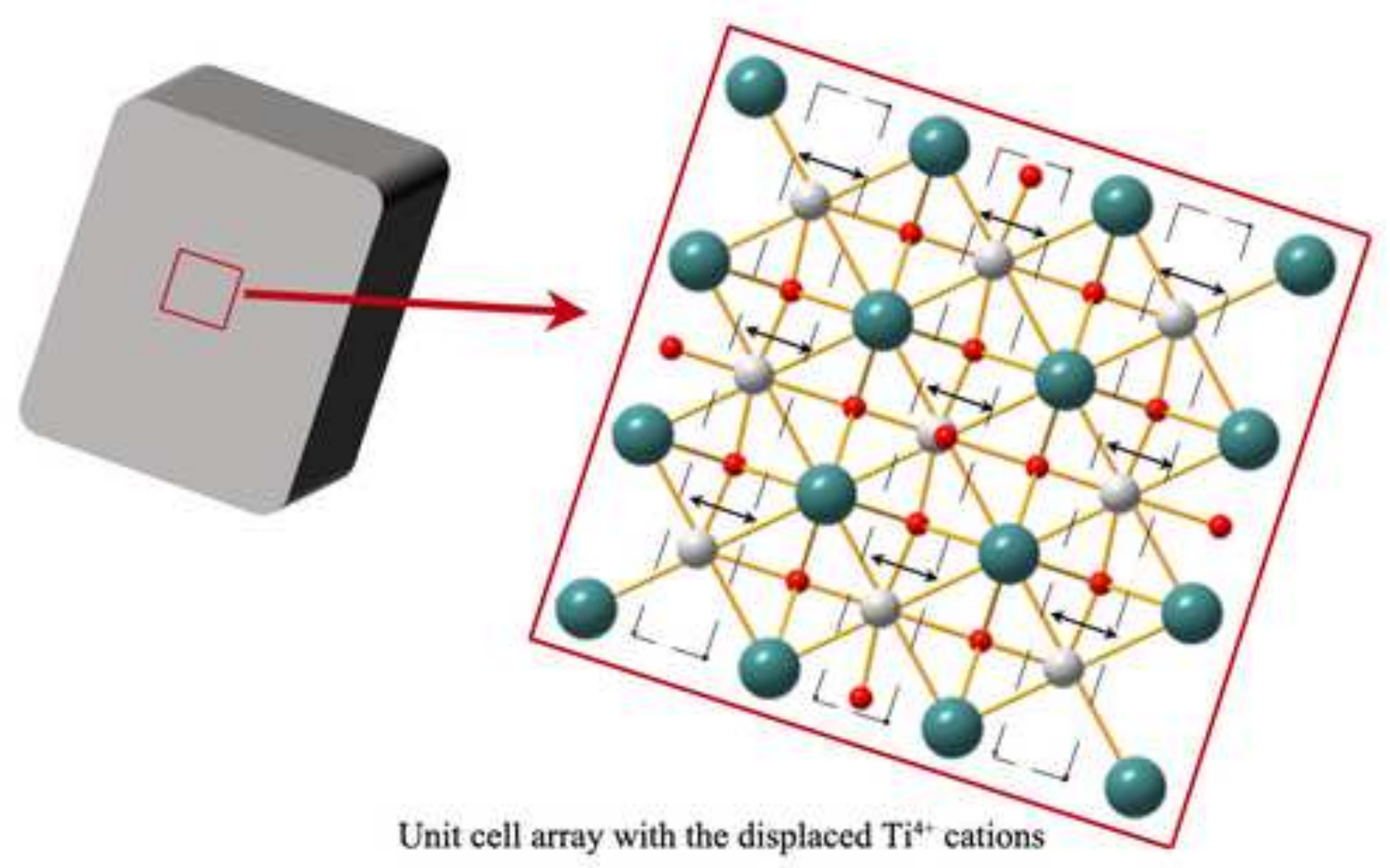



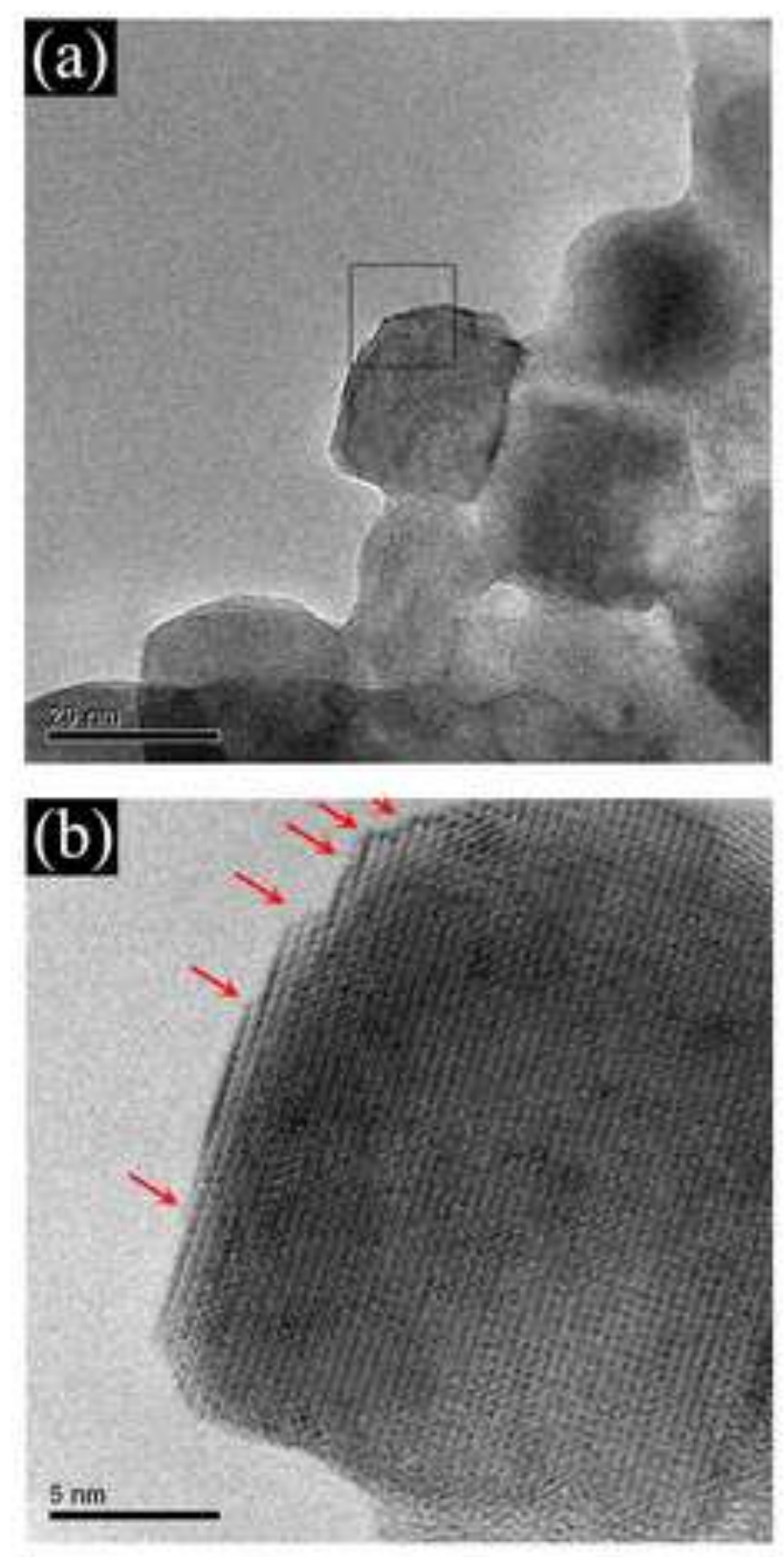

(c)

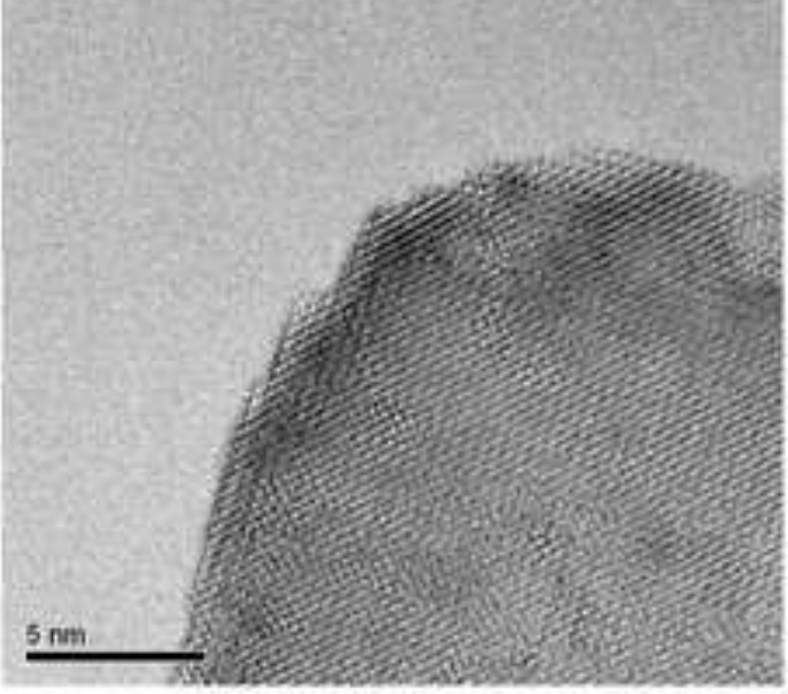

Figure 5 

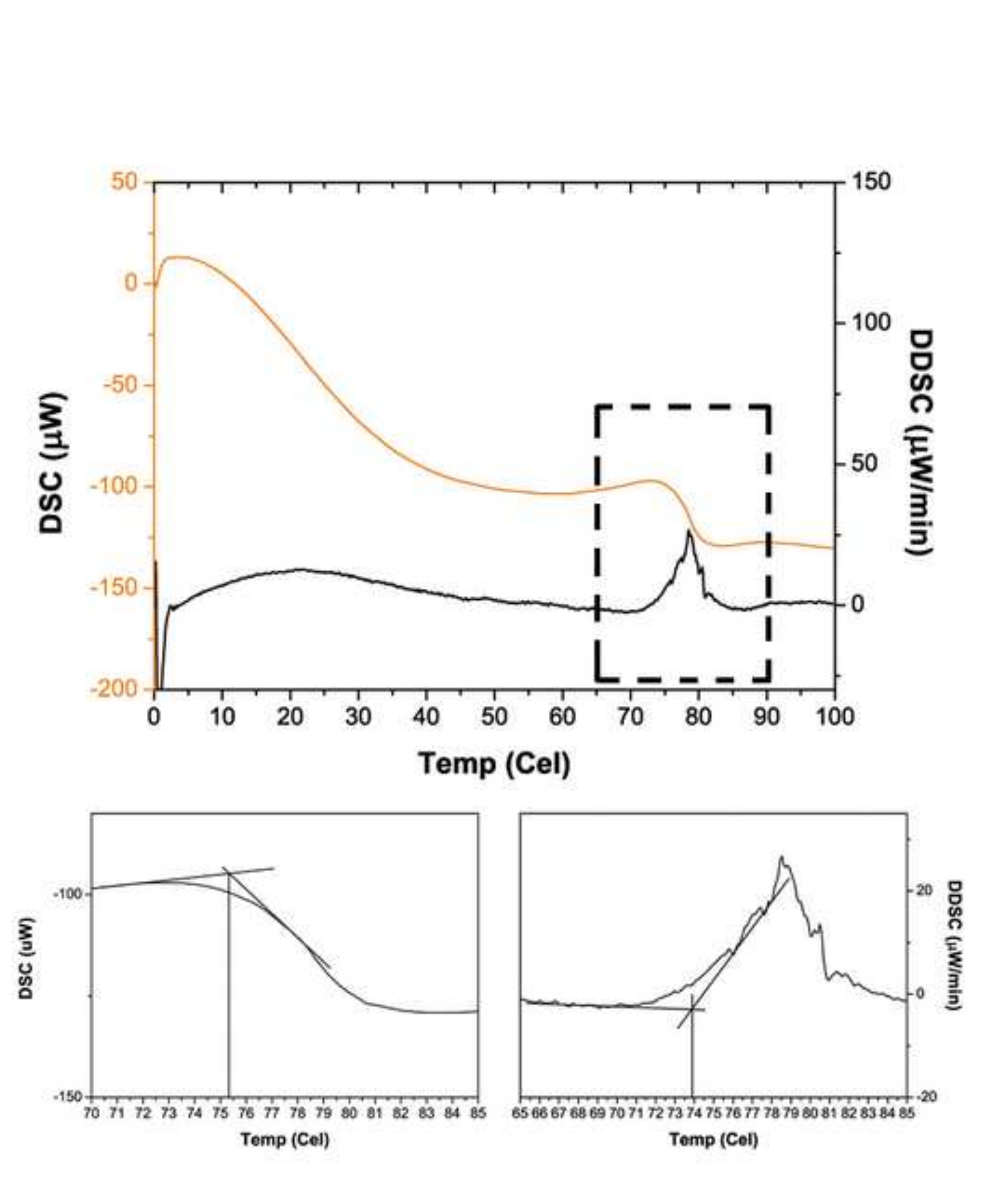

Figure 6

6

6

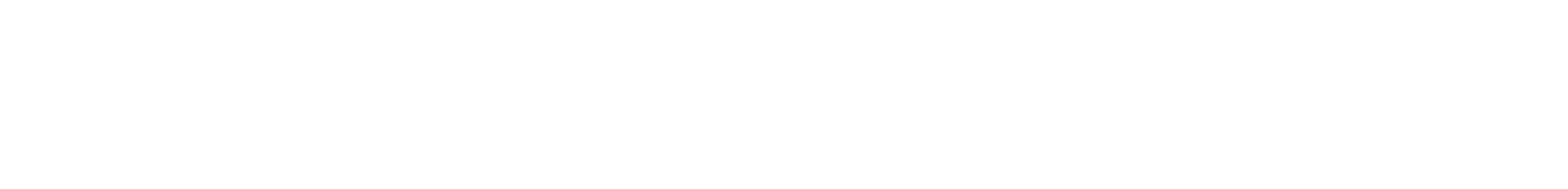

$$
\text { . }
$$

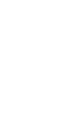

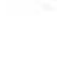

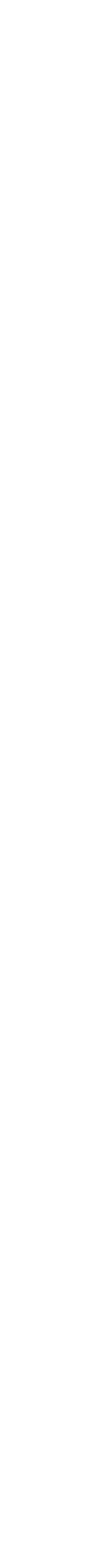

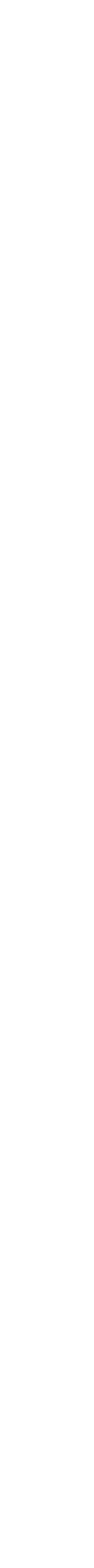




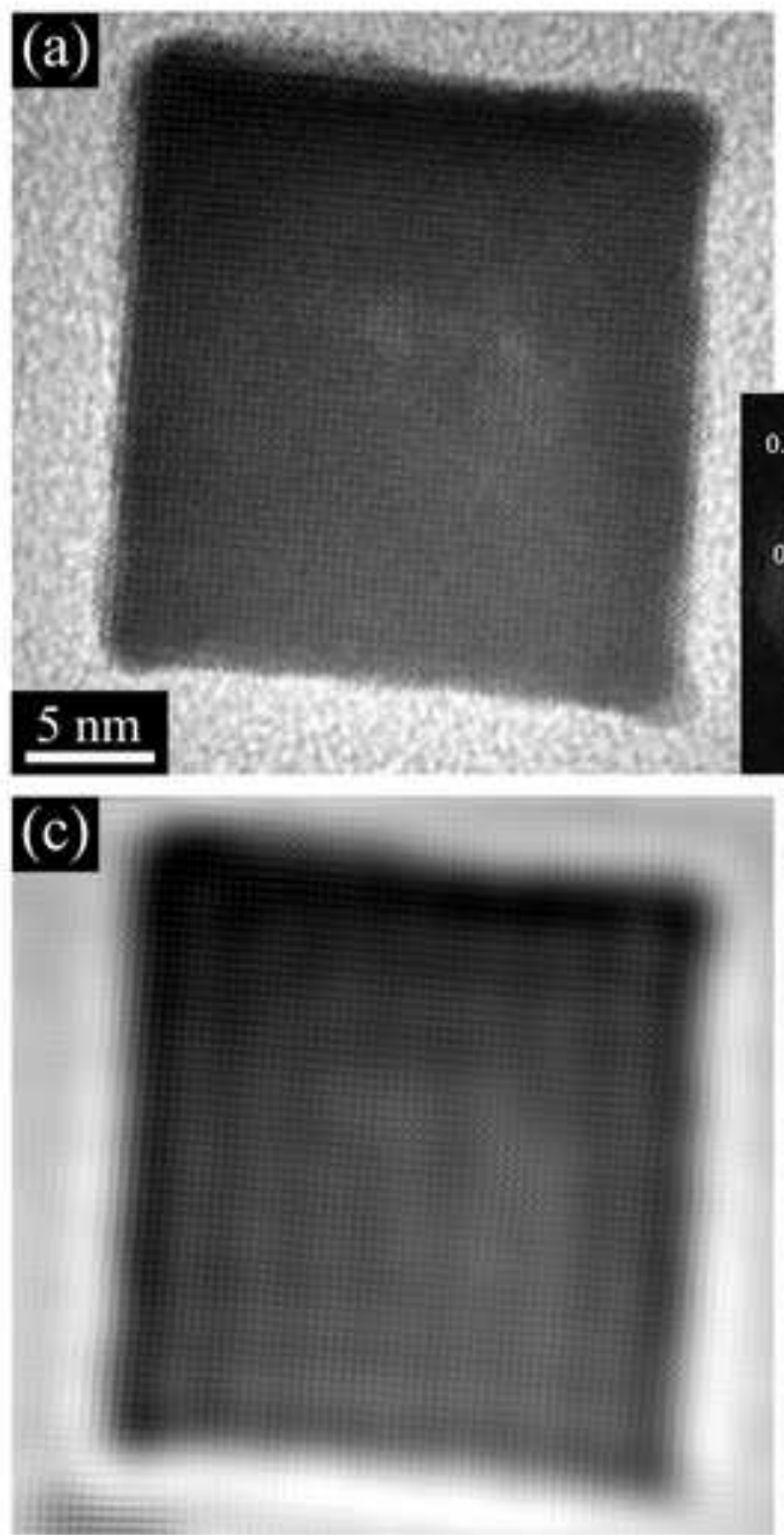

(b)

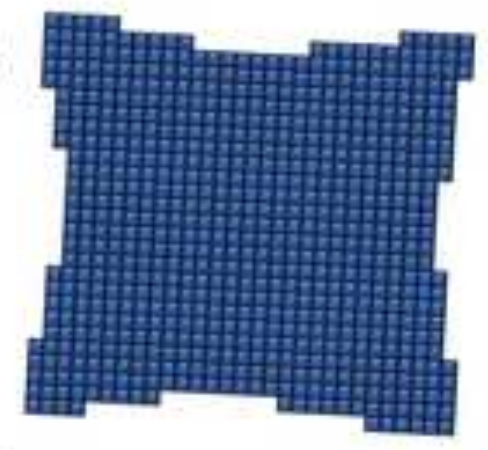

$0.250 \mathrm{~nm} \quad 0.397 \mathrm{~nm}$

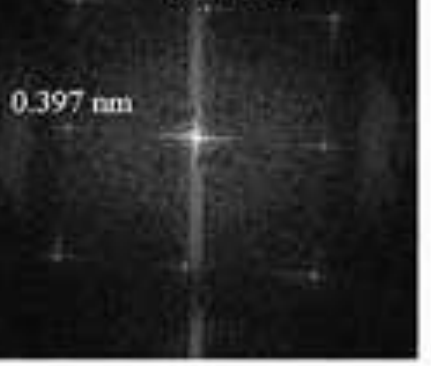

(d)

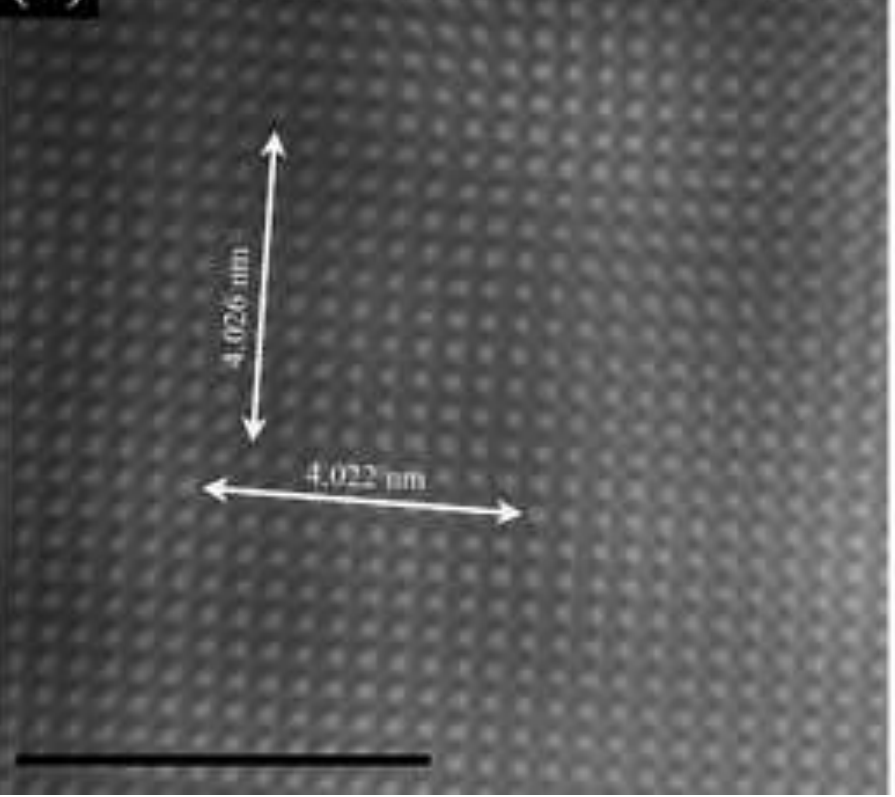


$\mathrm{BaTiO}_{3}$ nanocuboid
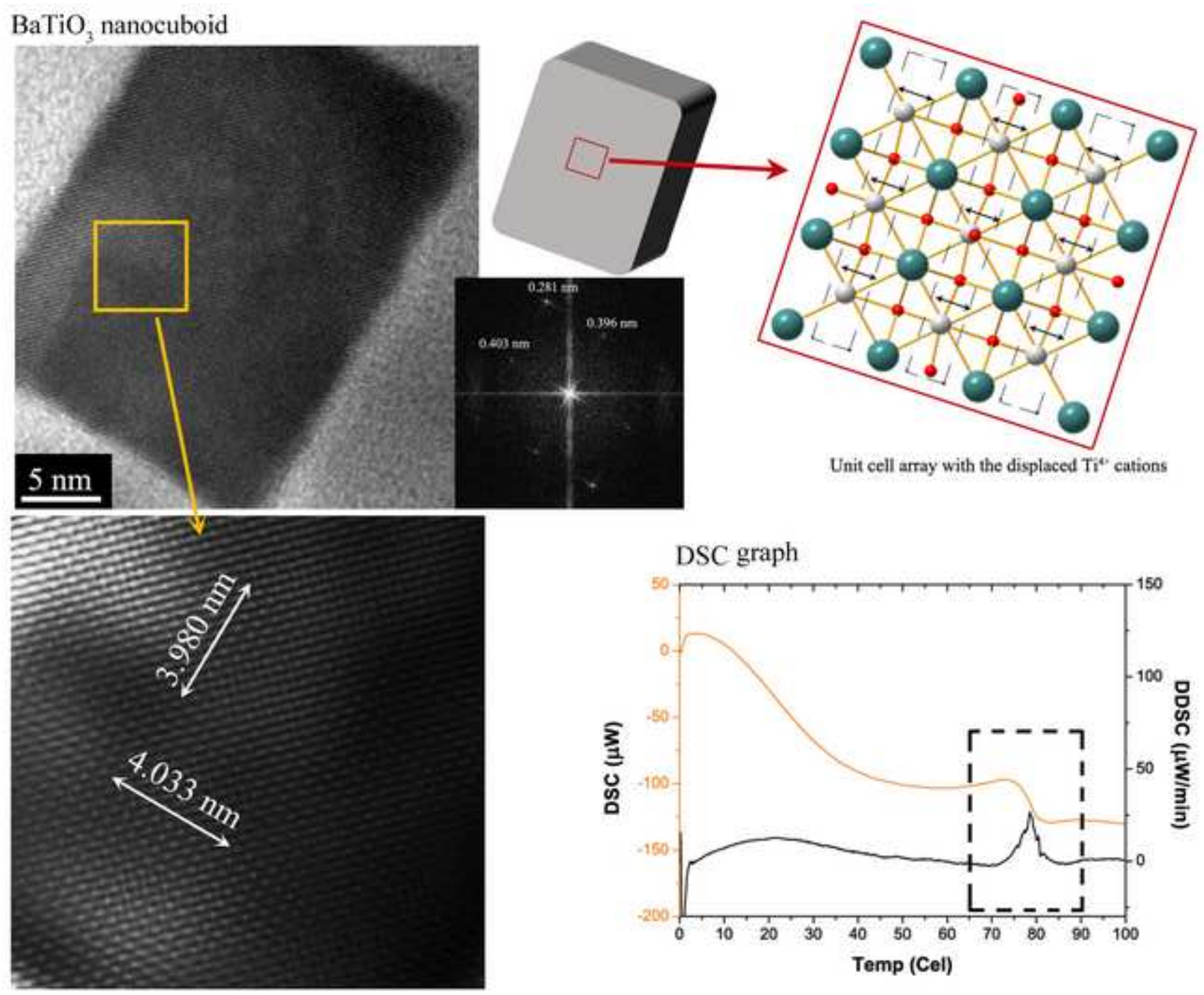

Unit cell array with the displaced $\mathrm{Ti}^{*}$ " cations

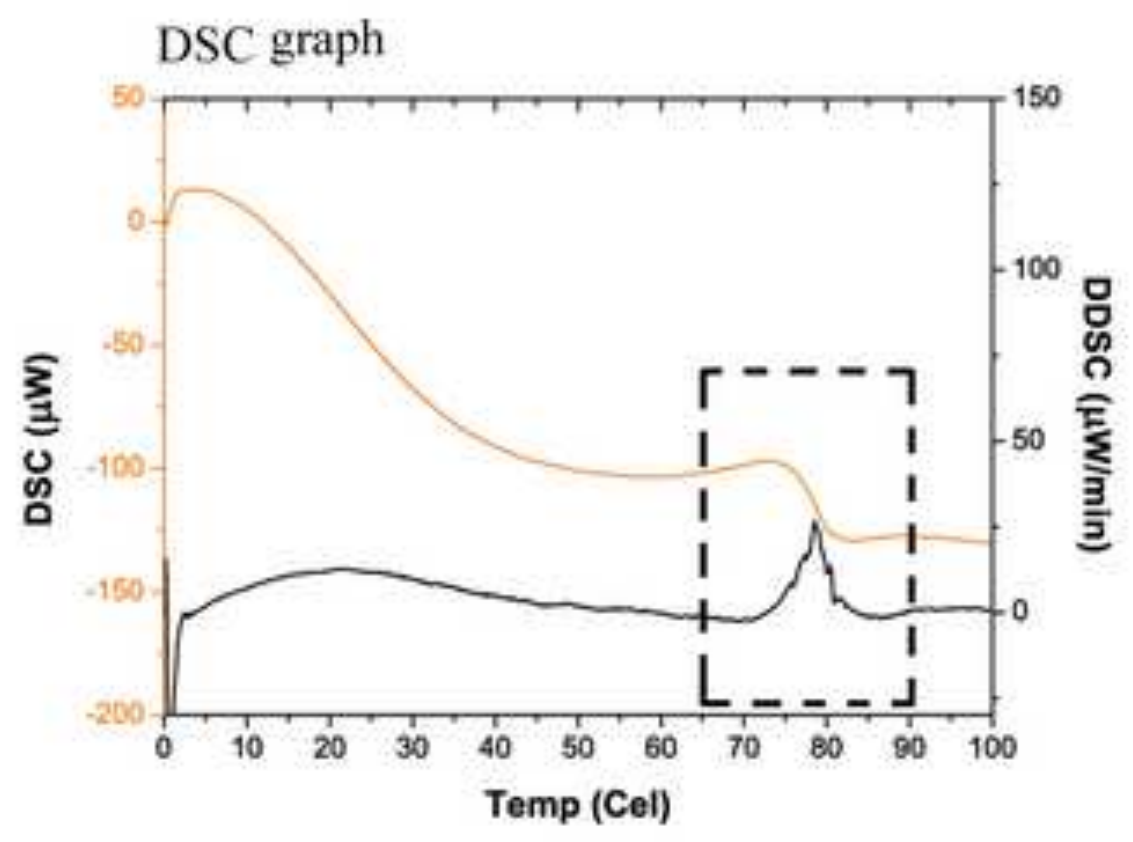

